\title{
Complexidades strathernianas
}

\author{
Renato Sztutman
}

O conteúdo de "Sobre o espaço e a profundidade”, de Marilyn Strathern, foi apresentado pela primeira vez em 1993 em um seminário da Universidade de Manchester, dando origem ao artigo publicado nove anos depois na coletânea organizada por John Law e Annemarie Mol: Complexities: social studies of knowledge practices. A publicação deste artigo manifesta $\mathrm{o}$ diálogo contínuo (e por vezes crítico) de Strathern com os estudos de ciência e tecnologia e, mais especificamente, com a "teoria-do-ator-rede", com a qual tanto Law como Mol mantêm conexóes explícitas. Em poucas palavras, esta é uma teoria que se quer imanente, pois não se separa das práticas de atores (actantes) por definição heterogêneos (humanos e não humanos), que se constituem em rede e compóem coletivos em escala variável. Estudar práticas de conhecimento, e não simplesmente teorias desgarradas das redes que as constituem, seria perseguir atores em suas gêneses, conexóes e desdobramentos, atentar para a feitura dos fatos e das ontologias, que se inscrevem em uma política. Com Complexities Law e Mol reúnem estudos sobre diversas práticas de conhecimento modernas, reunindo pesquisadores de áreas do conhecimento distintas - antropologia, sociologia, filosofia política, epistemologia, psicologia, entre outras - e produzindo uma intrigante comparação, focada tanto nos conteúdos como nas estratégias de análise.

Em "Sobre o espaço e a profundidade", o foco é lançado sobre a atividade de interpretação (enquanto especificação das qualidades singulares de algo - um evento, um lugar, um artefato), mais especificamente, a interpre- tação de imagens nas ciências biológicas e na antropologia, o que conduz a uma reflexão sobre os modos modernistas/euroamericanos de conhecer. Strathern toma como fio condutor considerações sobre quatro fotografias (tidas aqui como artefatos): duas delas extraídas de monografias antropológicas sobre povos melanésios, as outras duas, extraídas de um livro do fotógrafo Lennart Nillsson com imagens da gestação humana. Para Strathern, o ato de interpretar imagens - estas que têm ganhado grande destaque no rol da ciência e tecnologia modernas - revela um tipo particular de complexidade, e isso pode ser remetido aos processos de reversão figura-fundo a que este ato está sujeito, e que remontam a hábitos próprios da percepção humana. O que conta como figura ou como fundo em uma interpretação pode ser variável, desenhando relações instáveis. Uma figura estaria contida em um fundo, da mesma maneira que este fundo já habitaria a figura, esta reversão podendo ser compreendida sob um efeito de escala.

A reversão ou oscilação entre perspectivas (exemplificada pela reversão figura-fundo), bem como a multiplicação de níveis de simplicidade seriam marcas do que Law e Mol chamariam, com apoio nos estudos de ciência e tecnologia, de "complexidades". Eles resumem esta ideia da seguinte forma: "Há complexidade se as coisas se relacionam, mas não se somam, se os eventos ocorrem mas não em processos de tempo linear, e se os fenômenos partilham um espaço mas não podem ser mapeados em termos de um conjunto singular de coordenadas tridimensionais” (2002:1). Há complexidade 
quando se abre espaço para diferentes sortes de imprevisibilidades e singularidades impassíveis de serem inferidas de regras gerais ou leis universais, que fixam um campo ou "pano de fundo" como "natural", "dado", "universal", enfim, como medida para todas as coisas. Há complexidade quando, em vez de dualismos rígidos, antinomias hierárquicas ou situações de englobamento, revelam-se reversóes, alternâncias, oscilações.

Antes de tomar a complexidade como antídoto a todo esforço de simplificação - esforço realizado pelas ciências experimentais modernas, sobretudo aquelas que trabalham no interior de laboratórios -, Law e Mol propóem examinar a multiplicação de níveis de simplicidade como fenômeno verdadeiramente complexo. A idéia de complexidade estaria implicada, portanto, na de multiplicidade, e esta na de singularidade: haveria múltiplos níveis de simplicidade na medida em que se revelam múltiplos mundos e coordenadas (por exemplo as coordenadas espaço-temporais), e a complexidade passaria a residir nos modos de conexão entre esses mundos e coordenadas singulares, que não conduziriam a uma entidade sintética e unívoca. Segundo Law e Mol, a complexidade nas ciências sociais, como na Física, deve partir da recusa da hierarquia entre instância empírica (caso representativo) e teoria (acesso a um mundo geral). As especificidades seriam, assim, transferíveis e traduzíveis umas nas outras, mas sem com que isso as faça representar uma lei geral. Complexamente, o geral pode estar contido no particular, a ordem no caos, o espaço no lugar, o fundo na figura. (O espaço, afirma Strathern com referência ao trabalho do filósofo Edward Casey, não pode ser compreendido fora de um lugar experienciado. Assim como o tempo não se dissocia de uma história biográfica). E aqui voltamos ao tema de "Sobre o espaço e a profundidade": o apontamento de uma complexidade na interpretação, uma vez considerada a reversão figura-fundo e toda a fenomenologia da percepção que a embasa. Dimensóes “abertas à interpretação", produzindo efeitos de profundidade, e instâncias autoevidentes, gerando opacidade e por isso a impossibilidade de interpretação, não constituiriam posiçóes fixas, mas antes revelariam certas intenções interpretativas passíveis de serem examinadas.

As fotografias das quais Strathern se ocupa em "Sobre o espaço e a profundidade" tratam todas de um só tema, que remonta à reversão figura-fundo: a possibilidade de exteriorização de algo que está contido dentro de um corpo, mais especificamente, exteriorização de um embrião, um ser vivo no interior de um corpo feminino. Tudo se passa como se, à maneira de alguns rituais melanésios (sobre os quais a autora se debruçou em diversos momentos de sua obra), essas imagens refletiriam sobre como tornar visível o invisível. Duas fotografias de situações etnográficas (uma nas Montanhas Ok, feita por Maureen Kackenzie, outra no Monte Hagen, feita pela própria Strathern, ambas nas Terras Altas da Nova Guiné) focalizam artefatos (uma bolsa de corda usada por mulheres Ok para carregar tubérculos e crianças, uma coifa de penas e conchas portada por um dançarino Hagen) que, se interpretadas a partir dos dados etnográficos, deixam entrever uma analogia nativa, singular em cada caso, com o útero e, portanto, com a concepção humana. Strathern contrapóe a interpretação de uma ultrassonografia do ventre de uma mulher grávida à interpretação da fotografia de um casal que observa a projeção da imagem de seu embrião, fertilizado in vitro e prestes a voltar ao corpo da mulher (mãe). Da mesma maneira que um bebê que precisa ser extraído do corpo da mãe, essas imagens (como quaisquer outras) guardariam qualidades singulares, em maior ou menor profundidade, que precisam ser extraídas pelo espectador, seja ele o usuário de um 
serviço médico (um paciente), seja ele o leitor de um livro de fotografia ou antropologia. É na variação dessa relação de extração - nas intençôes interpretativas - que Strathern centra sua análise engenhosa. Interpretar é, segundo ela, esculpir um espaço dentro do espaço com menos ou mais profundidade. E interpretar a interpretação é compreender a construção desses espaços por meio de um arranjo entre figura e fundo, tendo em vista a relação entre a imagem e seu espectador.

Nessa sua "interpretação da interpretação", Strathern destaca a divergência entre posturas euroamericanas/modernas que ora buscam apreender todo significado como produto de interpretação, ora recusam a interpretação, apostando na autoevidência dos objetos retratados, no acesso certeiro ao mundo. A interpretação das fotografias "científicas" tornaria visível a oscilação entre essas posições: de um lado, com a ultrassonografia, o significado da imagem depende totalmente da interpretação (do diagnóstico) a um só tempo do aparelho e do médico que fazem um bebê existir; de outro, com a imagem das células de um embrião, a interpretação faz-se obsoleta, uma vez que o espectador reconhece como autoevidente o objeto com o qual se depara. Em um caso, o fundo engloba a figura (excesso de interpretação), em outro, a figura engloba o fundo (recusa da interpretação). Concentrando-se na fotografia de sua própria autoria, a da face decorada de um dançarino de Monte Hagen, Strathern admite uma oscilação, em sua própria interpretação, entre as duas posições extremas. No que se refere a fotos de "mundos outros", a interpretação sempre dependerá dos dados etnográficos, uma vez que o espectador dificilmente pode reconhecer diretamente o que vê. Ainda assim, pode oscilar entre uma atitude que prima pelo excesso de interpretação, mergulhando nas analogias indígenas que dão significado aos detalhes da imagem exibida, e uma atitude de recusa da interpretação, pautando-se simplesmente na ideia de que as situaçóes que ele vê - pessoas enfeitadas dançando, por exemplo - são autoevidentes, estão sob a garantia de um fundo tido como dado. De um lado, aposta-se na exploração da profundidade do campo, de outro, faz-se com que este fundo se torne opaco, naturalizando-o. Não seria possível garantir uma nitidez absoluta em quaisquer dos casos.

Strathern faz com que a análise destas fotografias, com suas diferentes profundidades de campo, empreste-se a um só tempo como acesso e como metáfora para pensar as práticas de conhecimento euroamericanas/modernas e, dentro delas, a própria prática da antropologia, que deve se deixar fecundar por práticas de conhecimento outras. "As estratégias figura-fundo da/o antropóloga/o", escreve ela, "podem certamente cruzar-se com as estratégias figura-fundo das pessoas que, de maneira diversa, fornecem a ele ou a ela profundidade ao seu material". A ideia de uma técnica por assim dizer complexa de interpretação (sempre referida aos hábitos da percepção) é, como a própria Strathern ressalta desde o início, fortemente inspirada por dois escritos de Roy Wagner sobre a reversão figura-fundo em imagens, visuais e não visuais. Estes escritos partem da mitologia, do ritual e da arte verbal dos povos Daribi e Usen Barok, povos estudados pelo autor. O sentido da complexidade revelado por Strathern é, assim, iluminado e reiterado por uma prática de conhecimento melanésia, o que revela uma estratégia analítica e discursiva que percorre as principais obras desta autora. Assim como em The Gender of the Gift e Partial Connections, livros seminais que exploram e torcem o sentido da comparação na antropologia, em "Sobre o espaço e a profundidade" acompanhamos Strathern construir seu pensamento por meio de cruzamentos instigantes: cruzamentos entre diferentes modos de interpretação, pondo lado a lado estratégias da ciência moderna, 
240 | Renato Sztutman

da antropologia, dos povos melanésios. As conexóes parciais dessas estratégias, longe de tentar estabelecer uma espécie de teoria geral ou método de interpretação, ilumina oscilaçóes e efeitos de escala. Como ela ainda escreve: "Eu não fiz mais do que apontar alguns efeitos de escala e ponderar a sua presença em alguns projetos atuais de 'compreensão' do mundo". Eis a complexidade da leitura de um texto de Strathern: acompanhar esses cruzamentos, oscilaçóes e efeitos de escala, tendo em vista o horizonte da reversão figura-fundo: o que parecia geral torna-se particular, o que parecia tema da análise torna-se operador do pensamento.

\section{autor Renato Sztutman}

Professor do Departamento de Antropologia / USP

Doutor em Antropologia Social / USP

Recebido em 06/11/2011

Aceito para publicação em 07/11/2011 